Original article

\title{
Evaluation of total abdominal hysterectomy over the decade in Holy Family Red Crescent Medical College Hospital - A retrospective observational study
}

\author{
Nazneen $\mathrm{R}^{1}$, Monir F ${ }^{2}$, Yeasmin $\mathrm{S}^{3}$, Akhter $\mathrm{S}^{4}$, Bakshi L ${ }^{5}$, Sultana $\mathrm{K}^{6}$
}

\begin{abstract}
Hysterectomy is the commonest major surgical procedure in Gynaecology \& usually performed to improve quality of life rather than to cure life-threatening conditions. The rates differ between countries depending on differences in morbidity, health economical aspects, traditions and attitudes. This retrospective observational study was carried out from 2001-2010 \& included all cases of abdominal hysterectomy done for benign and non emergency conditions in the department of Obstetrics \& Gynaecology, Holy Family Red Crescent Medical College and Hospital, Dhaka with the intention to assess the proportion and the indications of total abdominal hysterectomy over a 10-year period. Percentage of the total abdominal hysterectomy remained between 50-70\% of the total major operations over the decade. Fibroid was found to be the most common indication among the admitted patients (around 36\%) with highest percetage in 2006 and 2007 (43\% and $46 \%$ respectively). Next important indication was dysfunctional uterine bleeding (20\%) followed by pelvic inflammatory disease (13\%), ovarian mass (5\%), endometriosis \& adenomyosis (4\%) and post menopausal bleeding (2\%). The majority of hysterectomies were abdominal and the most common indication was uterine fibroids. The overall rate for hysterectomy remained reasonably stable.
\end{abstract}

1. * Dr Rumana Nazneen, Associate Professor

Department of Obstetrics \& Gynaecology, Holy Family Red Crescent Medical College and Hospital, Dhaka. Email : Rumana.nazneen@gmail.com

2. Dr Fahmida Monir, Assistant Health Officer Dhaka South City Corporation, Dhaka

3. Dr Salma Yeasmin, Assistant Professor, Department of Obstetrics \& Gynaecology, Holy Family Red

Crescent Medical College and Hospital, Dhaka

4. Dr Sharmin Akhter, Assistant Registrar, Institute of Child \& Mother Health, Matuail, Dhaka

5. Dr Lipy Bakshi, Registrar, Department of Obstetrics \& Gynaecology, Dhaka National Medical College, Dhaka

6. Professor Dr Kishwar Sultana, Professor of Obstetrics \& Gynaecology, Department of Obstetrics \&

Gynaecology, Holy Family Red Crescent Medical College and Hospital, Dhaka

*For correspondence
Keywords: Total abdominal hysterectomy, fibroid, surgery

\section{Introduction}

Hysterectomy is the commonest major surgical procedure in gynaecology with abdominal hysterectomy having the maximum share of 60 to 70 percent of the total. ${ }^{1}$ It is the second most surgical procedure in women worldwide and almost every third women in the US have undergone hysterectomy at the age of $60 .^{2}$ In 2003 , over 600,000 hysterectomies were performed in the United States alone, of which over $90 \%$ were performed for benign conditions. ${ }^{3}$ Approximately 100,000 hysterectomy are performed in the UK each year. ${ }^{4}$

In 1853 Ellis Burnham from Lowell, Massachusetts achieved the first successful abdominal hysterectomy. ${ }^{5}$ Initially mortality from hysterectomy was as high as $100 \%$ which was due to the absence of antisepsis, blood banking, modern anesthesia and the attainment of standardized methodologies. But gradually the technical evolution of abdominal hysterectomy underwent a number of stages. 6,7

In general, hysterectomies are performed to improve quality of life rather than to cure life-threatening conditions. The most common indications are heavy or irregular uterine bleeding, pelvic pain and pelvic pressure. These symptoms are often associated with uterine leiomyomas, endometriosis \& adenomyosis. However, the same symptoms also occur in the absence of identifiable disease which often has no pathological findings. ${ }^{8}$

The rate of hysterectomy differs not only between countries, but also within countries, depending on differences in morbidity, health economical aspects, traditions and attitudes ${ }^{9}, 10$ The difference ranges from 5.4 per 1000 women in the USA to 3.7 per 1000 in Italy and 1.2 per 1000 in Norway. The hysterectomy rate in developing countries is lower. Almost 20\% of women in these countries will have a hysterectomy by the age of 55 years. ${ }^{11}$

The types of hysterectomy include abdominal hysterectomy, hysterectomy with salpingo-oophorectomy, radical hysterectomy, supracervical hysterectomy, vaginal hysterectomy, laparoscope-assisted vaginal hysterectomy 
or robot-assisted laparoscopic hysterectomy. ${ }^{12}$ The choice of surgical approach depends upon clinical circumstances, surgeon's technical expertise and patient preference. ${ }^{13}$

The success of the operation may be limited by side effects, variations in patient compliance and the need for long-term therapy. Medications control but do not cure the problem. ${ }^{14}$

The improved hospital care, availability of blood transfusion, advanced anaesthesia and advancement of antibiotics has opened up a new era and thereby broadened the indications for hysterectomy with minimum post operative morbidity and mortality. In our country, hysterectomies are performed for more or less similar indications as those in advanced countries with the only difference being in the preoperative evaluation of the cases which is more on the clinical ground rather than modern investigations because of limited facilities and economical constraint. ${ }^{15}$ This study was carried out to assess the proportion and the indications of total abdominal hysterectomy over a 10 -year period.

\section{Methods}

This retrospective observational study was carried out in Holy Family Red Crescent Medical College Hospital on all the cases of abdominal hysterectomy done over the decade. Data of all the admitted patients from 2001-2010 were collected from the yearly statistical record book produced annually by the departments and the hospital. These included total number of indoor admissions, total number of patients admitted for gynaecological complaints, total numbers of major operations and total number of abdominal hysterectomies. Indications and other demographic data were noted. Patients with benign gynaecological problems who underwent abdominal hysterectomy were included and abdominal hysterectomy for emergency conditions e.g. obstetric haemorrhage and with malignant conditions were excluded.

The data were compared between 2001 and 2010. Age specific indications were analyzed in the year of 2010. P value was calculated from the Tables. Then $Z$ Test was done for statistical analysis using SPSS version. ${ }^{17}$ Significance level was set at $\mathrm{p}<0.05$. Study protocol was approved by institutional ethical committee.

\section{Results}

The total admitted patients over the period of 10 years through 2001-2010 was 33321. Out of which, total number of patients admitted for gynaecological complaints were 12433. Number of major operations done was 4768. Total abdominal hysterectomy done was 3167.

Rates of hysterectomy have not changed significantly over the years from 2001-2010. Overall percentage of hysterectomy remained between $50-70 \%$ of the total major operations. Rates for hysterectomy in 2001 were $57 \%$ and increased slightly to $67 \%$ by the year 2010 . Among these hysterectomies, fibroid uterus was the most common $(46 \%)$ indication. (Table-I)

Table I: Cumulative data over the period of 10 years in obstetrics \& gynaecology department of Holy Family Red Crescent Medical College Hospital (2001-2010)

\begin{tabular}{|c|c|c|c|c|c|c|c|c|c|c|c|}
\hline Variables & 2001 & 2002 & 2003 & 2004 & 2005 & 2006 & 2007 & 2008 & 2009 & 2010 & Total \\
\hline $\begin{array}{l}\text { Total } \\
\text { Admission }\end{array}$ & 3269 & 3172 & 3302 & 3351 & 3370 & 3188 & 3515 & 3353 & 3417 & 3384 & 33321 \\
\hline $\begin{array}{l}\text { Admitted } \\
\text { Gynae Patients }\end{array}$ & 867 & 1116 & 1047 & 967 & 1053 & 987 & 1264 & 1789 & 1867 & 1476 & 12433 \\
\hline Total operations & 823 & 1043 & 982 & 888 & 997 & 933 & 1005 & 972 & 1183 & 970 & 9796 \\
\hline $\begin{array}{l}\text { Major } \\
\text { Operations }\end{array}$ & 344 & 420 & 449 & 313 & 424 & 464 & 515 & 613 & 610 & 616 & 4768 \\
\hline $\begin{array}{l}\text { Abdominal } \\
\text { Hysterectomy }\end{array}$ & 197 & 291 & 320 & 201 & 302 & 329 & 357 & 361 & 417 & 401 & 3176 \\
\hline $\begin{array}{l}\text { Percentage of } \\
\text { Abdominal } \\
\text { Hysterectomy }\end{array}$ & $57 \%$ & $69 \%$ & $71 \%$ & $64 \%$ & $71 \%$ & $71 \%$ & $69 \%$ & $59 \%$ & $68 \%$ & $65 \%$ & $67 \%$ \\
\hline
\end{tabular}


Considering the age specific indications of hysterectomies in the year 2010, most of the abdominal hysterectomies were due to fibroid uterus $\&$ done during 3 rd and 4 th decade. It was followed by DUB, PID and adenomyosis, all of which were among the 41-50 yr age group. Hysterectomies due to PID were done mostly in 3rd decade. Hysterectomies done for endometriosis were more during 4th decade. Hysterectomies for chronic cervicitis were between $6-13 \%$ \& for post menopausal bleeding and cervical dysplasia were between 0-5 \% only. Same patient might have more than one indications. (table-II)

Table-II: Age distribution of patients undergoing hysterectomy in the year 2010. ( $\mathrm{n}=401)$

\begin{tabular}{|c|c|c|c|c|c|c|}
\hline $\begin{array}{l}\text { Age in } \\
\text { years }\end{array}$ & Fibroid uterus & DUB & PID & Adenomyosis & $\begin{array}{l}\text { Ovarian } \\
\text { tumour }\end{array}$ & Endometriosis \\
\hline $31-40$ & 46 & 15 & 23 & 11 & 5 & 1 \\
\hline $41-50$ & 80 & 32 & 16 & 16 & 6 & 4 \\
\hline $51-60$ & 3 & 11 & 1 & 0 & 1 & 0 \\
\hline$>60$ & 0 & 3 & 0 & 0 & 3 & 0 \\
\hline
\end{tabular}

The highest proportion of hysterectomy was done due to fibroid uterus (around 36\%). It was highest in 2007 (46\%). Next was due to dysfunctional bleeding, which was highest in 2001(25\%). Operations due to PID, adenomyosis and endometriosis increased slightly towards the end of the decade. (Figure-1)

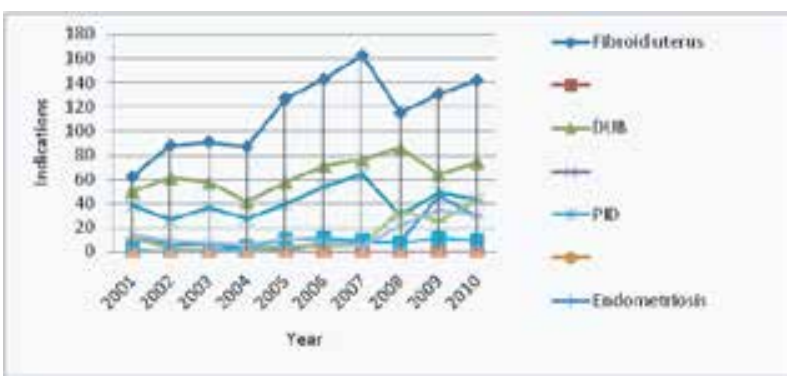

Figure-1: Hysterectomies from 2001 to 2010

Considering the post-operative complications calculated among 717 patients, urinary infection (12\%) was the most followed by abdominal pain (9\%), fever and wound infection ( $7 \& 6 \%$ respectively). Often the same patient developed more than one complications. (Table - III)

Table III: Post operative complications $(n=717)$

\begin{tabular}{lcc}
\hline Complications & $\begin{array}{c}\text { Number of } \\
\text { Patients }\end{array}$ & $\%$ \\
\hline Fever & 129 & 7 \\
Wound Infections & 110 & 6 \\
Urinary tract infection & 221 & 12 \\
Respiratory tract infection & 37 & 2 \\
Abdominal pain & 166 & 9 \\
Vault granuloma & 19 & 1 \\
Secondary haemorrhage & 37 & 2 \\
\hline
\end{tabular}

\section{Discussion}

Hysterectomy is recommended unless a uterine-sparing desire is expressed and accounts for $10 \%$ of the global rate of surgery. ${ }^{16}$ Laparotomy continues to be the preferred method for hysterectomy in approximately $60-70 \%$ of the cases. ${ }^{15}$

The data found in our study was comparable to the study done in other places. We found the proportion of abdominal hysterectomy done for fibroid was 36\%, for DUB was $20 \%$, for endometriosis was $4 \%$. Study done in Faisalabad, Pakistan showed that hysterectomy for DUB accounting for $43.3 \%$, for fibroid $26.7 \%$ and for endometriosis $1.7 \% .{ }^{4}$ The slight variation could be due to the basis of clinical diagnosis. Similarly in Nigeria, total abdominal hysterectomy accounted for $18.2 \%$ of all major gynaecological operations. The most common indications were uterine fibroid (60.6\%). Majority of the women were in their fifth decade of life (65.9\%). ${ }^{17}$ In our study it was found that $50-70 \%$ of major operations were abdominal hysterectomy \& most common indication was fibroid (36\%).

Another study showed abdominal hysterectomy done for uterine myomas were $54.6 \%$ and for benign ovarian tumors were $5.46 \%$ which is comparable to our study. A total of $74.77 \%$ of the patients subjected to abdominal hysterectomy were aged 36 to $55 .{ }^{18}$

A study done in our country by Ishrat $S$ showed that common indications were fibroid (28\%) \& DUB 21\%. ${ }^{19}$ Study done by Timothy L showed the indications as fibroid 53\%, adenomyosis $18 \%$ and ovarian tumour $16 \% .^{20}$ Similar incidence was also seen in the studies by Gupta. ${ }^{21}$ Study done by Shergill in India showed that the commonest indication was fibroid and DUB (26\%). ${ }^{22}$ 
Hysterectomy due to post menopausal bleeding and cervical dysplasia was found to be between $0-5 \%$ in our study where as it was $1.2 \%$ in US community hospitals. ${ }^{23}$ Same study showed hysterectomies done for other reasons were $6.4 \%$ where as in our study it was $7-9 \%$ for other reasons e.g. chronic cervicitis.

The cumulative proportion of complications in our study was $39 \%$, out of which, fever with or without wound infection, urinary and respiratory tract infection was $27 \%$. Study done by others showed the complication rate in hysterectomies was $24.21 \%$ out of which fever was $25.98 \% .{ }^{18}$ In our study it was evident the proportion of urinary tract and wound infection were $12 \%$ and $6 \%$ respectively. Study done in district general hospitals in Shire counties, two in outer London and one in London teaching hospital showed that urinary infections (25\%) and wound infections (25\%) were the commonest complications. ${ }^{24}$ A study in united states showed $6 \%$ to $25 \%$ of abdominal hysterectomies developed an infection post surgery. 25

The majority of hysterectomies were abdominal and most common indication was uterine fibroid. The overall rate of hysterectomy remained reasonably stable. The study was done in a single hospital. A multi centre analysis would have been more accurate. Some post operative data could not be collected due to drop out of patients.

\section{References}

1. Singh KC, Barman SD, Sengupta R. Choice of hysterectomy for benign disease, Department of Obstetrics and Gynaecology, University College of Medical Sciences. Delhi, India. J Obstet Gynaecol. 2004; 54:365-70.

2. Forsgren C. Hysterectomy on benign indications and pelvic floor dysfunction-clinical and epidemiological aspects. Thesis for Doctoral degree.Karolinska Institute Stock Holme, Sweden. 2010.

3. Wu JM, Wechter ME, Geller EJ, Nguyen TV, Visco AG. Hysterectomy rates in the United States, 2003. Obstet Gynecol.2007;110 (5): 1091-5.

4. Roohi M, Qureshi S, Tahira T. Abdominal hysterectomy : Performed by postgraduate trainees. Professional Med J. 2007; 14(4): 685 - 8.

5. Sutton C. Hysterectomy: a historical perspective. Baillieres Clin Obstet Gynaecol. 1997; 11(1):1-2.

6. Miyazawa K. Technique for total abdominal hysterectomy: historical and clinical perspective. Obstet Gynecol Surv. 1992; 47:433-447.
7. Richardson EH. A simplified technique for abdominal panhysterectomy. Surg Gynecol Obstet. 1929; $48: 248-51$.

8. Michel C, Malik B, Eric L, Fabrice N, Gilles C. Hysterectomy for Benign Lesions: What is left for the abdominal route? Journal of Gynecologic Surgery. 2001; 17 (4): 109-14.

9. Davis A, Magos A. The Hysterectomy lottery. J Obstet Gynaecol. 2001; 2:166-70.

10. Persson P, Hellborg T, Brynhildsen J, Fredrickson M, Kjolhede P. Attitude of mode of hysterectomy - A survey based study among Swedish gynaecologists. Acta Obstet Gynaecol Scand. 2009; 88: 267-74.

11. Hysterectomy: Common surgical procedures. John Hopkins Medicine. Health Information. Available from : http : // www. hopkinsmedicine. org / healthlibrary/conditions /adult / surgical _ care/ common_surgical_procedures_85,p01392.

12. Thomas GS, William JM. Abdominal hysterectomy. UpTo Date. Walter Kluwer. Available from: http : // www. uptodate. com / contents / abdominal hysterectomy-beyond-the-basics

13. Editorial. Hysterectomy - Still a Useful Operation. NEJM. 2002; 347(17):1360-62 .

14. Dewan F. Evaluation of 100 cases of hysterectomy. Dessertation. Bangladesh College of Physicians \& Surgeons.

15. Santiago D, Antonio P. Overview of Current Trends in Hysterectomy. Expert Rev of Obstet Gynecol. 2009; 4(6):673-85.

16. Anzaku AS, Musa J. Total abdominal hysterectomy for benign gynaecological conditions at a University Teaching Hospital in Nigeria. Niger J Med. 2012; 21(3):326-30.

17. Chryssikopoulos A, Loghis C. Indications and results of total hysterectomy. $1986 ; 71(3)$ : 188-94.

18. Ishrat $S$, Khan T. Evaluation of indications of Abdominal Hysterectomy performed in Chittagong Medical College Hospital. JCMCTA. 2008;19 (2) : 7-11.

19. Timothy L, Chin R, Kunasegaran K. A Review of Clinical Benefits of Total Laparoscopic Hysterectomy and Total Abdominal Hysterectomy. Clinical audit, 2010. Department of Obstetrics \& Gynaecology. Hospital Sultan Abdul Halim. Kedah. Malaysia p13.

20. Gupta G, Kotasthane D, Kotasthane V. Hysterectomy: A Clinico-Pathological Correlation Of 500 Cases. The Internet Journal of Gynecology and Obstetrics. 2009;14(1). Available from : https : //ispub.com/IJGO/14/1/8173 
21. Shergill SK, Shergill HK, Gupta M, Kaur S. Clinicopathological study of hysterectomies. J Indian Med Assoc. 2002; 100(4) : 238-9.

22. Cynthia M. Farquhar, Franzcog A, Claudia A. Hysterectomy Rates in the United States 1990-1997. Obstetrics and Gynaecology. 2002; 99(2): 229 - 234

23. Clarke AL, Black N, Rowe P, Mott S, Howle K. Indications nd outcome of total abdominal hysterectomy for benign disease: a prospective cohort study. BrJ Obstet Gynaecol. 1995; 102(8):611-20.
24. Rice CN, Howard CH. Complications of hysterectomy. US Pharm. 2006; 31(9):HS16-HS24.

25. Hysterectomy. National Women's Health Network. Available from: www.nwhn.org/ healthinfo /detail.cfm?info_id=8\&topic=Fact $\% 20$ Sheets . Accessed August 7, 2008. 